\title{
Diabetes Mellitus: A Review on Pathophysiology, Current Status of Oral Medications and Future Perspectives
}

\author{
Mehmet Evren Okur ${ }^{\star 1,2}$, Ioannis D. Karantas ${ }^{3}$, Panoraia I. Siafaka ${ }^{4}$ \\ ${ }^{1}$ Department of Pharmacology, Faculty of Pharmacy, University of Anadolu, 26470, Tepebaşı, Eskişehir, Turkey \\ ${ }^{2}$ Eskişehir State Hospital, Odunpazarı, Eskişehir, Turkey \\ ${ }^{3}$ Ippokratio General Hospital, B Clinic of Internal Medicine, Thessaloniki, 54124 , Greece \\ ${ }^{4}$ Laboratory of Polymer Chemistry and Technology, Department of Chemistry, Aristotle University of Thessaloniki, \\ 54 124, Thessaloniki, Greece
}

\begin{abstract}
Diabetes mellitus (DM), belongs to the class of metabolic diseases which the main symptom associated with this disease is the high sugar levels in blood for a long period. It can be categorized to the world's major diseases considering that affects high population in earth and presents two main types I and II. Diabetes complications include possible blindness, amputation of lower limb, renal failure, and cardiac arrest or stroke. This review summarizes the pathophysiology for both types of DM, the variety of antidiabetic medications as well as future perspectives. Until now injectable medications are more frequently used in order to achieve the desirable treatment. Patients prefer oral antidiabetic medications since are easier to be administered and for this reason researchers focus their studies at this direction. This work also aimed to present and evaluate possible oral formulations against DM type II.
\end{abstract}

Keywords: Diabetes mellitus, Epidemiology, Medications, Current status

\section{INTRODUCTION}

\section{Diabetes, epidemiology and pathophysiology}

Recently, it was recorded that only in 2012 at least 1.5 million deaths induced from diabetes ${ }^{1}$. The terms "Diabetes" and "Mellitus" are derived from Greek language. "Diabetes" denotes "a passer through, a siphon" whereas the "Mellitus" means "sweet". It is believed that Greeks entitled it such way, due to the exaggerated urine proportions produced by diabetic patients which attracted flies and

${ }^{*}$ Corresponding author: Mehmet Evren Okur

E-mail address: evrenokurecz@gmail.com 
bees $^{2,3}$. From the very first described case of DM 3000 years ago by the ancient Egyptians and Araetus of Cappadocia (81-133AD) to 1675 when British Thomas Willis rediscover the sweetness of urine and blood of patients ${ }^{4,5}$, since now huge improvement in the knowledge for DM has been achieved. Some theories support that economic ${ }^{6}$ and insurance ${ }^{7}$ status would play a major role on the express of DM (type II). Moreover a recent study showed that race would also have an important factor on DM prevalence (type I and II) ${ }^{8}$.

DM is a serious, chronic and complex illness characterized by hyperglycemia that resulted from the pancreatic $\beta$-cells generate deficient insulin (a hormone that adjusts blood glucose) when the body cannot efficiently custom the insulin or both of them ${ }^{1,9,10}$. World health organization has categorized DM as the $7^{\text {th }}$ leading cause in USA while it was estimated that 422 million adults present diabetes in 2014, 4 times higher than the recorded cases in $1980^{1}$. Clinicians also believe that DM may be occurred by the carbohydrates and fat existence in daily diet given that starch digestion in mammals is accomplished by a-amylase and a-glucosidase. Inhibition of starch digestive enzymes or glucose transporters can reduce glucose release and absorption in the small intestine. This decrement could help to manage $\mathrm{DM}^{11,12}$.

Although, DM is one of the highest health crisis of the 21st century the majority of ministries and public health authorities keep being oblivious for the current impact of this disease and its complications. Table 1 summarizes the estimation diabetic patients at 2015 and 2040. In developed countries, approximately $87 \%$ to $91 \%$ of the diagnosed diabetic people are estimated to have type II diabetes, $7 \%$ to $12 \%$ present type 1 diabetes while $1 \%$ to $3 \%$ to have other types of diabetes. In under developed and developing countries the relative cases of type I and type II diabetes have not been studied in great detail. Nonetheless, it seems that type I diabetes is less frequent than type II diabetes, as well as it is increasing by almost $3 \%$ each year globally. It has been correlated that in most developed countries, the greater part of DM cases in toddlers and juveniles are associated with type I diabetes whereas type II diabetes is reported as a more common condition. Mostly, type II diabetes presence has been elevated alongside accelerated sociocultural alterations: ageing populations, increasing people living in urban areas, low physical activity, increased sugar consumption as well as low fruit and vegetable intake ${ }^{1,13}$.

The exact cause of DM is uncertain until now. Nevertheless, scientists believe that genes, environmental factors and other pathological conditions such as autoimmune eradication of the pancreatic $\beta$-cells which provoke insulin deficiency and other abnormalities which cause resistance to insulin action seems to involve in the development of the disease $\mathrm{e}^{9,10,14}$. 
Table 1: IDF Diabetes Atlas global estimates, 2015 and $2040^{1}$

\begin{tabular}{|c|c|c|}
\hline & 2015 & 2040 \\
\hline Total word population & 7.3 billion & 9.0 billion \\
\hline Adult population (20-79 years old) & 4.72 billion & 6.16 billion \\
\hline Child population (0-14 years old & 1.92 billion & - \\
\hline Diabetes (20-79 years) & 2015 & 2040 \\
\hline Global prevalence & $8.8 \%(7.2-11.4 \%)$ & $10.4 \%(8.5-13.5 \%)$ \\
\hline Number of people with diabetes & $\begin{array}{l}415 \text { million } \\
\text { (340-536 million) }\end{array}$ & $\begin{array}{l}642 \text { million } \\
\text { (521-829 million) }\end{array}$ \\
\hline Number of deaths due to diabetes & 5.0 million & - \\
\hline $\begin{array}{l}\text { Health expenditure due to diabetes } \\
\text { (20-79 years) }\end{array}$ & 2015 & 2040 \\
\hline $\begin{array}{l}\text { Total health expenditure, } \\
R=2^{*} 2015 \text { USD }\end{array}$ & 673 billion & 802 billion \\
\hline $\begin{array}{l}\text { Hyperglycaemia in pregnancy } \\
(20-49 \text { years) }\end{array}$ & 2015 & 2040 \\
\hline Proportion of live births affected & $16.2 \%$ & - \\
\hline Number of live births affected & 20.9 million & - \\
\hline $\begin{array}{l}\text { Impaired glucose tolerance } \\
\text { (20-79 years) }\end{array}$ & 2015 & 2040 \\
\hline Global prevalence & $6.7 \%(4.5-12.1 \%)$ & $7.8 \%(5.2-13.9 \%)$ \\
\hline $\begin{array}{l}\text { Number of people with impaired } \\
\text { glucose tolerance }\end{array}$ & $\begin{array}{l}318 \text { million } \\
(212.2-571.6 \text { million })\end{array}$ & $\begin{array}{l}481 \text { million } \\
\text { (317.1-855.7 million) }\end{array}$ \\
\hline Type I diabetes (0-14 years) & 2015 & 2040 \\
\hline $\begin{array}{l}\text { Number of children with type } 1 \\
\text { diabetes }\end{array}$ & 542,000 & - \\
\hline $\begin{array}{l}\text { Number of newly diagnosed } \\
\text { cases each year }\end{array}$ & 86,000 & - \\
\hline
\end{tabular}

The main symptoms of DM marked hyperglycemia combined with polyuria, polydipsia, polyphagia also known as the 3 P's signs. The presence of the 3 P's could indicate that the blood sugar level is high. In type I, 3 P's can be observed in higher rate while they can be developed quickly. In type the 3 signs are nearly undetectable and develop more gradually. Not so often, weight loss, blurred vision as well as susceptibility to infections could also be aroused by chronic hyperglycemia. The most acute complication of uncontrolled DM which could be 
threatening to the life is the hyperglycemia accompanied with ketoacidosis or the nonketotic hyperosmolar syndrome. Diabetic patients may also have high blood pressure and anomaly of lipoprotein metabolism. Among other long-term symptoms, retinopathy with possible vision loss, nephropathy inducing kidney failure, peripheral neuropathy related with the presence of foot lesions, amputations, and Charcot joints. Furthermore autonomic neuropathy generating gastrointestinal, genitourinary, and cardiovascular signs and sexual dysfunction can coexist to diabetic patients. Finally, people diagnosed with DM appear usually atherosclerotic cardiovascular, peripheral arterial, and cerebrovascular diseases ${ }^{9,10,14}$.

\section{Classification and diagnosis of diabetes}

Three main types of DM are known type I associated with full insulin deficiency, type II-progressive insulin deficiency ${ }^{15}$ and gestational DM which is diagnosed in $2^{\text {nd }}$ or $3^{\text {rd }}$ semester of pregnancy. Currently, although type I cannot be prevented, type II is preventable with good health, exercising and healthy diet. Early diagnosis is the key in diabetes management. Nevertheless, type II have affected high population and lead to complications in several body parts, heart, nerves, eyes, kidney and so on ${ }^{16}$. Diabetes falls into three below general categories:

1. Type I diabetes is as a result of $\beta$-cell destruction which customarily provoke complete insulin insufficiency. It was formerly known as insulin-dependent, juvenile or childhood-onset diabetes and it is occasioned by an autoimmune reaction, in which the immune system invaded against the insulin-producing pancreatic beta cells. Type I diabetes is distinguished by deficient insulin production in the body. In such type of DM the patients require daily administration of insulin so as to normalize the glucose level in the blood. Have not taken the insulin, their life is being threatened and can be fatal. The reason of type IDM is not identified yet being presently not preventable. Albeit, the reasons for type I diabetes are still unclear, changes in environmental risk factors and/or viral infections may have an impact on the appearance of DM. Extreme urination and thirst, continuous hunger, weight loss, vision changes and fatigue are the main symptoms of this type of DM. More often than not, the number of people who diagnosed with type I diabetes is escalated.

2. Type II diabetes which earlier termed non-insulin-dependent or adult-onset diabetes, assumed to be a result from a continuous insulin secretory defect on the background of insulin resistance on account of the body's inefficient use of insulin. Type II diabetes is the most typical DM. In this type, the body is capable of producing insulin but becomes so resistant that the insulin is ineffective. By the time, insulin levels could subsequently turned out insufficient. The cause of 
high blood glucose levels are both the insulin resistance and deficiency. Given that the symptoms (coincidental to type I diabetes symptoms) are generally less noticeable or absent, the illness could be dismissed and be undiagnosed for numerous years, and not until complications have already ascended. For various years, type IIDM was observed only in adults, nowadays it has started to be seen also in children. Until present the exact causes for the development of type II diabetes are unknown, some significant risk factors being pointed out. The most significant ones include: excess body weight, physical inactivity and poor nutrition. Other factors which impacted are ethnicity, family history of DM, past history of gestational diabetes and advancing age $\mathrm{e}^{1,13,17-19}$.

3. Gestational diabetes mellitus (GDM) is a type of DM determined in the second or third trimester of pregnancy that is not clearly overt diabetes. GDM is a provisional disorder that happens in pregnancy and brings enduring danger of type II diabetes ${ }^{2,18}$.Women with slightly elevated blood glucose levels are diagnosed as having gestational diabetes, whilst women with substantially elevated blood glucose levels are classified as having diabetes mellitus in pregnancy. GDM tends to arise from the 24th week of pregnancy. Screening by means of an oral glucose tolerance test is therefore recommended and must be conducted early in pregnancy for high risk women, and between the $24^{\text {th }}$ and $28^{\text {th }}$ week of pregnancy in all other women. Women with hyperglycemia diagnosed during pregnancy are at greater risk of adverse pregnancy outcomes such as: very high blood pressure and foetal macrosomia, with the vaginal birth being difficult and risky. In some cases, clinicians prescribe insulin or oral medication in order to control the blood glucose levels. Notwithstanding, gestational diabetes normally disappears after delivery but women who have been previously diagnosed are in danger of presenting GDM in subsequent pregnancies and type IIDM later in their life. In addition, infants beared by mothers with GDM also have a higher risk of developing type II diabetes during adolescence or early adulthood ${ }^{1,13,18,19}$.

\section{Diagnostic Tests for Diabetes Mellitus}

DM could be set on diagnosis mainly formed on $\mathrm{A} 1 \mathrm{C}$ criteria or plasma glucose criteria, the fasting plasma glucose (FPG) or the 2-h plasma glucose value after a 75-g oral glucose tolerance test (OGTT). The same diagnostics are utilized to screen for and diagnose DM as well as to detect individuals with prediabetes $9,10,14,18,19$. The American Diabetes Association (ADA)/European Association for the Study of Diabetes (EASD) and the American Association of Clinical Endocrinologists (AACE) suggest an HbA1c level of b7.0\% and $\leq 6.5 \%$, respectively, for decreasing the risk of diabetic compromises in most patients ${ }^{20-22}$.Table 2 shows criteria in order to diagnose prediabetes and diabetes. 
Table 2: Criteria for the Diagnosis of Prediabetes and Diabetes ${ }^{19}$

\begin{tabular}{|c|c|c|c|}
\hline & Normal & Prediabetes & Diabetes \\
\hline A1C & $\leq 5.6 \%$ & $5.7-6.4 \%$ & $\geq 6.5 \%$ \\
\hline FPG & $\leq 99 \mathrm{mg} / \mathrm{dL}$ & $100-125 \mathrm{mg} / \mathrm{dL}(5.6-6.9 \mathrm{mmol} / \mathrm{L})$ & $\geq 126 \mathrm{mg} / \mathrm{dL}(7.0 \mathrm{mmol} / \mathrm{L})$ \\
\hline OGTT & $1313 \leq 139 \mathrm{mg} / \mathrm{dL}$ & $\begin{array}{l}100-140-199 \mathrm{mg} / \mathrm{dL}(7.8-11.0 \\
\mathrm{mmol} / \mathrm{L})\end{array}$ & $\geq 200 \mathrm{mg} / \mathrm{dL}(11.1 \mathrm{mmol} / \mathrm{L})^{*}$ \\
\hline RPG & RPG & & $\geq 200 \mathrm{mg} / \mathrm{dL}(11.1 \mathrm{mmol} / \mathrm{L})^{\star *}$ \\
\hline
\end{tabular}

*In the absence of unequivocal hyperglycemia, results should be confirmed by repeat testing.

**Only diagnostic in a patient with classic symptoms of hyperglycemia or hyperglycemic crisis. RPG, random plasma glucose.

\section{Complications of Diabetes mellitus}

DM may induce several complications or can co-exist with other diseases. In everyday clinical management of diabetic patients, doctors battle with diabetic complications which are very common and come in broad spectrum of manifestations. The complications are divided in microvascular and macrovascular. The macrovascular, which are more severe, are coronary disease, stroke and peripheral neuropathy. The microvascular are sneakier and in long-term maylead on macrovascular complications are diabetic retinopathy, diabetic nephropathy and diabetic foot. In this part several case reports are present among the numerous found in the literature. Neonatal diabetes is a rare form of diabetes mellitus (DM) which might occurs during the first six months of infant's life. The two forms permanent and transient have been associated with alterations in the KCNJ11 and ABCC8 genes most frequently and in the GATA6 gene less frequently. These mutations coexist with gastrointestinal and heart abnormalities. Such is a report of a Caucasian male infant with a GATA6 mutation that developed DM due to pancreatic hypoplasia, ventricular and atrial septal defect, an absent gallbladder and a right inguinal hernia ${ }^{23}$.

DM was also correlated with Friedreich's ataxia (FA). A14-year-old male adolescent had insulin-dependent DM on a FA background, while being under treatment with insulin. Studies have shown that islet pancreatic cells reduction that happen in FA is the cause of $\mathrm{DM}^{24}$. There are cases that pancreatic neuroendocrine tumor (PNET) was connected with DM developing. Such is a case of a patient with a pancreatic somatostatin tumor ${ }^{25}$.

ABCC8 mutation in a homozygous state was also connected with DM. The insulin-dependent DM that occurs due to this mutation can be misinterpreted with neonatal DM, although its beginning is later. In those patients sulfonylurea treatment was chosen as primary medication ${ }^{26}$. 
Despite diabetic striatopathy is a common complication on adults was only reported twice in children. In those cases along with weight loss, polyuria, and polydipsia was reported hemichorea-hemiballism that was receded after glucose control ${ }^{27}$.

Among others taking right clinical history of a patient and not only the lean on the lab results for diabetic patients is quite important. A 37-year-old man with many diabetic complications and trouble in glucose regulation was misdiagnosed as DM type I while he was suffering from Neonatal DM as long as two weeks old. The proper taking of the family history revealed that his mother and his brother was also suffering from the same problem. This will help the patient now on his family making options ${ }^{28}$. In another report, a Caucasian woman, 55 years of age without medical history and not ever under any medication, presented with signs of diabetic retinopathy and high blood glucose. Patient's lab tests were found normal. The clinical history revealed recent appearance of polyuria and polydipsia. That set the diagnosis of DM type I which should always be in the front line of a medical doctor's thinking. However, in this case did not conformed with the patient's age ${ }^{29}$. Another category of DM complications is the infections. This category includes bone infections such as patellar osteomyelitis. Two reports of patellar osteomyelitis were revealed, both in adult diabetic women with uncontrolled blood glucose and no formerly medical history. The two patients presented with knee pain and after lab and screening tests were found that they suffered from patellar osteomyelitis. Both were treated with surgery and oral antibiotics with good prognosis. It is believed that diabetic neuropathy which causes dwindling or absence of pain is one factor of the late doctor's consultation. It remains to be found the reasons of the increased frequency of bone and other systemic infections in patients with $\mathrm{DM}^{30}$.A rare complication that was recorded on a DM patient was Cryptococco$\operatorname{sis}^{31}$. This is a common fungal infection on patients that are under chronic immunosuppressant therapy. A 48-year-old man with a lung mass suspected to be cancer had that infection. Cryptococcosis can appear on immunocompetent patients only with a predisposing background and DM is one of them. Another uncommon fungal infection is mucormicosis which has been proven to present more often to DM patients. It remains to be investigated the reasons that this occurred ${ }^{32}$.

\section{Update Guidelines for DM treatment}

The 2016 Guidelines for Diabetes treatment according to American Diabetes Association are very certain and not controversial ${ }^{33}$. Similar to those are the guidelines of European Association for the Study of Diabetes. The presented guidelines are in most common use and the majority of clinicians obey on them. Firstly, for DM type I the main course of treatment include only insulin in vari- 
ous forms: the fast acting involve Lispro, Aspart, Glulisine, the long acting Detemir, Glargine, Degludec and finally the intermediate acting insulin.

For the DM type II the guidelines contain 4 stages which are not meant to be used on the same patient. At the first stage metformin is the cornestone of the treatment. If the target of HbA1c level is not reached in 3 months clinician should add a second drug from the following categories DPP-4 inhibitors, Thiazolidinediones, Sulfonylureas, SGLT2 inhibitors, GLP-1 receptor agonist and basal insulin (stage 2). On third stage (also three months later) and only if the HbA1c level target is not yet reached, a third drug should be used from a different category. Eventually, on the fourth stage (after three months of stage 3 ) and the HbA1c is above the treatment level the course of treatment consists of metformin, basal insulin and mealtime insulin or GLP-1 receptor agonist.

In fact, there are two major reasons for a clinical doctor to deviate from the guidelines above. The first one is when the patient reveals an allergic reaction to one of medication. In this case they should consider to alter the drug category or moving to the next stage. The second case is when the patient suffers from another condition (which is very common among diabetic patients) and cannot receive a medication from a certain category because it has a contraindication for that condition. The most important part among treatment is the patient to discipline as in drug reception as in the diet.

\section{Current Status on Medications for Type I and II Diabetes mellitus}

Howbeit, there is a variety of pharmacological agents for the type II diabetic patients to choose, for type I patients the list is too short. The most significant limitation on antidiabetic treatment is the type of drug administration. Whether insulin formulation was oral then many patients could have a better quality of life. In most cases insulin is the only proposed way in order to reduce the glucose levels. Many researchers now mainly focused on improving the quality of these patients by using novel pharmacological agents. Every patient diagnosed with type I requires lifelong insulin therapy which three main categories are the rapid-acting insulin, long-acting insulin and intermediate options to be chosen. It was 10 years ago when FDA approved an injectable medication known as pramlintide, for people diagnosed with type I diabetes and insulin-treated patientswith type II. Amylin is a natural hormone derived from the pancreatic beta cells and is the hormone which synthetic pramlintide was based on. Pramlintide act as follows: "It is administrated after the meal holding it longer in the stomach, promoting weight loss which keeps the blood glucose level low while also suppress the glucagon production”. Until today the main approved treatments for type I DM is insulin and Pramnlitide. However some researchers believe that Metformin 
and Sodium Glucose Co-Transporter 2 Inhibitors approved for type II DM could also be involved for type I DM ${ }^{34,35}$. Medications of type II DM include several active ingredients and not only insulin. As it was already referred diabetes type II could complicate the health of the patients and affect a huge adult population. The majority of diabetic people are treated with glucose-lowering medication in order to decrease the long-term compromises.

The main classes of diabetes therapeutics are seven with the main differentiations of such medications include safety, glucose-lowering, type of delivery (oral or injectable) and so on. The history of type II diabetic formulations is long since the first use of synthetic guanidine to take place on $1918^{5}$. After almost one century, new drugs against type II diabetes based on peptides have been approved from FDA. A brief history of diabetes type II medications is presented in Table 3.

It is widely known between clinicians and patients that insulin is the primary choice for the treatment of type I diabetes. Nonetheless, insulin use is not only limited for type I but can also be applied for type 2 diabetic patients. This is fact when the other antidiabetic formulation does not fulfill the criteria to low blood glucose. The main categories as already reported in literature are also demonstrated in Table 3. Moreover, what researchers should evaluate is the limitation on oral medications and this is why many pharmaceutical technologists and companies target on oral administration of antidiabetic drugs.

\section{Biguanides}

Biguanides are organic compounds with the chemical formula shown in Figure 1. Their application as antidiabetic drug is historical long. Although, metformin the most significant analogue of biguanides was known for its antidiabetic properties since 1959, it was not commercially available before late 9os. Metformin mechanism involves the reduce of hepatic glucose production, improve insulin sensitivity as well as peripheral glucose utilization ${ }^{5,16,36,37}$. Metformin use in Type $2 \mathrm{DM}$ may be associated with reduced cancer mortality rates. It lowers $\mathrm{A} 1 \mathrm{C}$ by $1-2 \%$ and can be used in combination with most other glucose lowering agents ${ }^{38}$.

\section{Pharmaceutical formulations for the delivery of metformin}

Metformin is aqueous soluble molecule which limited its sustained use as matrix. In current status, researchers try to avoid the burst release in order to extent the utility of the tablets. It is commonly known that sustained release is quite important for oral pharmaceutical products in order to avoid the frequent dosage.

Sustained release dosage form prepared by wet granulation method including a variety of hydrophilic macromolecules such as Hydroxyl-propyl methylcellulose (HPMC) K15M, HPMC K10oM and HPMC K200M) and Polyacrylate poly- 
mers, Eudragit RL100 and Eudragit RS100 were investigated as drug delivery system of Metformin controlled administration. The in vitro release studies of the above system indicated that the combination of this material may modify the dissolution rate $^{39}$. An extended release tablet containing metformin was successfully prepared via melt granulation combining the hydrophobic stearic acid and hydrophilic poly(ethylene oxide). The matrix tablet formulation showed a controlled drug release profile ${ }^{40}$. Solid dispersions of metformin hydrochloride developed with methocel K100M were investigated also as alternative carrier for the antidiabetic molecule. These carriers prepared by solvent evaporation and co-grinding method revealing that the polymer ratio affected the drug release rate $^{41}$. Similar solid dispersions were also formulated by solvent evaporation and closed melt method, using Compritol 888 ATO as the polymer. Solvent evaporation led to sustained release ${ }^{42}$. Gastro retentive floating tablets containing metformin were produced via wet solid dispersion methodology with cellulose derivatives such as HPMC K4M, HPMC K15M in different ratios, sodium bicarbonate and citric acid gas generating agents and other excipients. Floating tablets were prepared by wet solid dispersion method. Adjusting different parameters the release is controlled whereas the formulations are stable ${ }^{43}$.

Table 3: Brief history of type II diabetes pharmacological agents ${ }^{5}$

\begin{tabular}{lll}
\hline Year & Active Ingredient & Category of medications \\
\hline before 1920s & no effective drugs & - \\
\hline 1921 & $\begin{array}{l}\text { first commercially } \\
\text { available insulin in USA }\end{array}$ & Hormones \\
\hline 1946 & Insulin & Neutral protamine Hagedorn- \\
\hline 1950 & Tolbutamide & Sulfonylureas \\
\hline 1959 & Metformin & Biguanides \\
\hline 1996 & Troglitazone & Thiazolidinediones \\
\hline 1997 & Repaglinide & Meglitinides \\
\hline 1995 & Acarbose & $\alpha$-Glucosidase Inhibitors \\
\hline 2005 & Pramlintide & Amylin Agonists \\
\hline 2008 & Colesevelam & Bile acid sequestrants \\
\hline 2009 & Bromocriptine & Dopamine agonist \\
\hline 2013 & Canagliflozin & Sodium GlucoseCo-Transporter 2 Inhibitors \\
\hline 2014 & Dapagliflozin & Sodium Glucose Co-Transporter 2 Inhibitors \\
\hline 2016 & Lixisenatide & Peptide \\
\hline
\end{tabular}


<smiles>[R2]N([R])C(=N)NC(=N)N</smiles>

Figure 1: Chemical formula of biguanides

Among the antidiabetic properties metformin also applied as anticancer agent against liver cancer. Gold nanoparticles (AuNPs) were conjugated with hyaluronic acid (HA) and loaded with Metformin on HA capped AuNPs (H-AuNPs). These nanoparticles have an affinity to easily bind on the surface of the liver cancer cells, exhibiting promising results ${ }^{44}$.

\section{Sulfonylureas}

Sulfonylureas (SU) appearance was found in 1937 when some doctors observe their properties as hypoglycemic agents. Its chemical formula can be seen in Figure 2. Their mechanism of action is to trigger insulin release from pancreatic b-cells ${ }^{45}$ In addition can decrease the hepatic glucose production and the uptake of hepatic insulin while can increase the glucagon secretion by pancreatic $\alpha$-cells ${ }^{5}$ The main drawback of SU is that can induce hypoglycemia due to the excess of insulin production and release. First generation drugs include acetohexamide, carbutamide, chlorpropamide, glycyclamide (tolhexamide), metahexamide, tolazamide and tolbutamide while as second generation drugs classified glibenclamide (glyburide), glibornuride, gliclazide, glipizide, gliquidone, glisoxepide and glyclopyramide. Glimepiride may be considered as third generation drug ${ }^{46}$.<smiles>[R]NC(=O)NS(=O)(=O)c1ccc([R])cc1</smiles>

Figure 2: Chemical formula of sulfonylurea

\subsubsection{Pharmaceutical formulations for the delivery of sulfonylureas}

In most case sulfonylurea agents are lipophilic molecules which their low solubility decrease their bioavailability and therapeutic efficacy. Pharmaceutical technology purposed to improve their water solubility by the preparation of solid dispersions and other pharmaceutical formulations. More specifically, solid dispersions of the glibenclamide were developed by solvent evaporation utilizing hydrophilic polymers as PEG 6000, PVP K30, sorbitol, mannitol, man- 
nitol, citric acid and urea in various concentrations. The results depicted that the amorphous formulation present high dissolution rates ${ }^{47}$. Solid dispersion via solvent evaporation and micronized techniques were applied so as to improve oral absorption of the poorly soluble, glimepiride. The release studies illustrated that the two methods were able to enhance and extend the release rate while the formulations were bioequivalent with a marketed product ${ }^{48}$.

Furthermore, controlled release matrices of glipizide were synthesized from ethyl cellulose via the direct compression method. Various co-excipients such as HPMC K10oM, starch and CMC, were also studied. It was investigated that the release was enhanced ${ }^{49} \mathrm{Atenolol}$ and Glyburide were both encapsulated in hard gelatin capsule by direct compression method using Avicel, Lactose DC, Crospovidone and Magnesium Stearate in various ratios. Some formulations showed that can improve patient compliance by improving the ease of two drugs administration together ${ }^{50}$ An enhancement on the solubility of glipizide was aroused after being dispersed with the help of the hydrophilic poloxamer, cyclodextrin, and povidone. The optimized candidate was further entrapped into non-effervescent floating tablets (NEFT) with the use of crospovidone and release retarding agents like HPMC and PEO. In-vitro buoyancy and release studies demonstrated that non-effervescent floating drug carriers can be a promising method so as to extent the gastric retention time and enhance bioavailability of glipizide ${ }^{51}$ Several systems incorporated Glibenclamide based on spray congealing were formulated with the use of sufficient excipients, solid at room temperature, as Myverol, Myvatex, Gelucire. Cremophor EL and Poloxamer 188 were selected as surfactants and PEG 4000 as co-solvent. Researchers believe that the spray congealing is an auspicious novel manufacturing technique of solid self-emulsifying systems ${ }^{52}$.

Microcapsules of gliclazide-deoxycholicacid using sodium alginate were studied for their efficiency and size, release kinetics, stability and swelling studies at various $\mathrm{pH}$ and temperatures. The micro-carrier displayed colon-targeted delivery and the addition of deoxycholic acid prolonged gliclazide release suggesting its suitability for the sustained and targeted delivery of both molecules to the lower intestine ${ }^{53}$.

\section{Meglitinides}

Meglitinide (Figure 3) have a similar mechanism action to reduce glucose production as sulfonylureas but they did not present similar chemical formula. They have a weaker binding affinity and faster dissociation from the sulfonylureas binding site ${ }^{54}$. The main analogues of Meglitinides are repaglinide, nateglinide and mitiglinide. 
<smiles>COc1ccc(Cl)cc1C(=O)NCCc1ccc(C(=O)O)cc1</smiles>

Figure 3: Chemical formula of Meglitinide

\section{Pharmaceutical formulations for the delivery of Meglitinides}

Repaglinide present very short half time limited such way its use. Consequently, preparing a controlled release formulation seems important issue. Sustained release pellets of Repaglinide comprised from Avicel, lactose and different polymers were synthesized via extrusion-spheronisation method. The optimized pellet was orally administrated to normal and diabetic rats, decreasing the blood glucose in both normal and diabetic rats throughout 8-12 $\mathrm{h}^{55}$. Nanoemulsion of repaglinide was characterized as a hopeful carrier for RPG for persistent hypoglycemic effect since showed better hypoglycemic effect in comparison to tablet formulation in experimental diabetic rats ${ }^{56}$ Moreover, repaglinide encapsulated floating microspheres were investigated as safe, economical and improved bioavailable formulation showing important $(\mathrm{p}<0.01)$ reduce in blood glucose in contrast to pure drug treated group ${ }^{57}$.Repaglinide-loaded solid lipid nanoparticles (SLNs) were manufactured with a variety of surfactants (Stearic acid and glyceryl mono stearate, phosphatidylcholin, Tween8o, Pluronic F127, poly(vinyl alcohol) and poly(vinyl pyrrolidone) and characterized in vitro. It was resulted that the phosphatidylcholin-based SLNs reveal extended drug release time and the highest loading capacity. The drug dissolution rate was slow from all formulation $\mathrm{s}^{58}$. Nano-crystal formulations of repaglinide were manufactured using soluplus as a stabilizer and KolliphorE-TPGS as an oral absorption enhancer. Nano-crystal formulations revealed significant $(\mathrm{p}<0.001)$ hypoglycemic activity with faster onset (less than 30 $\mathrm{min}$ ) and prolonged duration (up to $8 \mathrm{~h}$ ) compared to neat repaglinide ${ }^{59}$.

\section{Thiazolidinediones}

Thiazolidinediones (TZD) or glitazones, belong to the medications of type II diabetes. Their chemical structure consists of thiazolidine groups (Figure 4) which produce the main action of these active ingredients. Their mechanism of action involve activation of peroxisome proliferator-activated receptor (PPAR gamma), a nuclear receptor. This action change the transcription of several genes play a role in glucose and lipid metabolism and energy balance ${ }^{60}$. The main derivatives of TZDs are Pioglitazone, Rosiglitazone and Lobeglitazone. 
<smiles>CCc1ccc(CCOc2ccc(CC3SC(=O)NC3=O)cc2)nc1</smiles>

Figure 4: Chemical formula of pioglitazone

\section{Pharmaceutical formulations for the delivery of Thiazolidinediones}

Pioglitazone use for more than one year may have an increased danger to provide bladder cancer as FDA warned. However, some formulations are still under experimental design especially to prolong the release.

$\mathrm{N}$-Acyloxymethyl derivatives of pioglitazone were applied as extended-release injectable system. It was found that but acyroyloxymethyl derivative was efficiently converted to pioglitazone as it was established from in vitro rat plasma with a half-life of less than $2 \mathrm{~min}$ at $37^{\circ} \mathrm{C}$, whereas the level of enzymatic cleavage in rat plasma declined as the ester chain length improves for the longer acyloxymethyl derivatives. The researchers suggested that palmitoyloxymethyl derivative of pioglitazone can be potentially applied as injectable medication in order to treat diabetes ${ }^{61}$. Cyclodextrine complexes of glimepiride) and pioglitazone were studied in order to enhance drug release properties as it was finally proved right $^{62}$. Further, an in-situ injectable and biodegradable triple-interpenetrating network (3XN) hydrogel, was developed in order to deliver rosiglitazone which was comprised from dextran, teleostean and N-carboxyethyl chitosan. The dissolution ability was reported as sustained for the model drug ${ }^{63}$.

\section{Glucosidase Inhibitors}

Alpha-glucosidase inhibitors are mainly delivered to the patients via oral route so as to decrease blood glucose. Alpha-Glucosidase Inhibitors inhibit alpha- glucosidases that convert polysaccharide carbohydrates into monosaccharides in upper GI system. These drugs slow the absorption of glucose. Acarbose, was the first medication approved by FDA in 1995 and miglitol was following in 1996. Their use is quite limited because they must administer in multiple daily doses while some gastrointestinal (GI) side effects have been recorded.

\section{Pharmaceutical formulations for the delivery of a-Glucosidase Inhibitors}

Researchers synthesized microspheres rosiglitazone maleate with desirable yields between 69 and 75\%, high entrapment, precarious size distribution, and seductive target release as promising carrier for diabetes management ${ }^{64}$. Among others a-Glucosidase Inhibitors can be found in several plant extract. Literature findings indicate this opinion. Nineteen plants derived from Fabaceae family, 
which were applied in Thai traditional medicine for DM management, showed a-glucosidase inhibitory activity via enzymatic reaction ${ }^{65}$. A commonly popular medicinal herb which exhibit $\alpha$-glucosidase inhibitory activity is Radix Astragali $^{66}$. Pistagremic acid was isolated from the dried galls extract of P. integerrima showing which is the molecule for the antidiabetic property ${ }^{67}$.

\section{Sodium-glucose transporter-2 inhibitors}

The sodium-glucose transporter-2 (SGLT-2) inhibitors (SGLT-2i) have been newly categorized as antidiabetic agents. SGLT2 is a human protein in humans which inhibit the glucose reabsorption in the kidney, enhancing glucose excretion, and finally decrease blood glucose levels. Canagliflozin (2013), dapagliflozin (2014) and empagliflozin (2014) have taken approval from FDA and EMA for type II diabetes. Diabetic patients could control the glucose levels along with exercise and a healthy diet ${ }^{5,68-70}$. Furthermore, SGLT inhibitors could offer additional options for the achievement of DM management. However, due to their new existence pharmaceutical technologists have not yet evaluated any formulations related with such proteins.

\section{Incretin based-therapies}

Incretins consist a group of hormones (the two main are GLP-1 and glucosedependent insulinotropic peptide) produced by GI that raise insulin secretion in a glucose-dependent manner. Incretin-based therapies focused on GLP-1 consider that native GLP-1 does not present high pharmacological value. This is because of the low half-time of GLP due to its degradation by the peptidase enzyme DPP-4. Two significant strategies have been proposed to control GLP-1-mediated effects: the inhibition of DPP-4, improving the half-life of GLP-1 (DPP-4 inhibitors) and use of glucagon-like peptide-1 receptor agonists (GLP-1 agonists) which can provide supra physiological stimulation of the GLP-1R.Incretin based strategies can enhance the glycemic control with low incidence of hypoglycemia and without fatten. According to some researchers DPP-4 and GLP-1 therapies are more advantageous than metformin ${ }^{71}$. Until now, formulations of incretinbased therapies have not been found in the literature.

\section{Dipeptidyl peptidase -4 Inhibitors}

DPP-4 Inhibitors are oral hypoglycemic agents inhibit in DPP-4 enzyme and are not considered as the initial therapy for type II DM. Their applications and formulations are quite new, almost one decade. The first FDA approved drug was sitagliptin with the newest candidate of this class Omarigliptin being commercially available in 2015. DPP-4I mechanism of action involve increment of incretin levels which hinder glucagon release, followed by insulin secretion, re- 
duced gastric emptying and decrement of blood glucose levels ${ }^{72,73}$. A recent study showed that patients with severe renal impairment may be improved after DPP$4 \mathrm{I}$ administration ${ }^{74}$. Among other recorded side-effects such as pancreatitis, angioedeama, anaphylaxis ${ }^{75}$ at 2015 FDA warned that some patients could present sever joint pain. Consequently, safety of DPP-4 use is still under investigation although their numerous advantages.

\section{Glucagon-like peptide-1 receptor agonists}

These injectable analogues are also known as GLP-1 receptor agonists or incretin mimetics. Their mechanism of action is to agonists the GLP-1 receptor. Nowadays, the approved agonists are: exenatide, liraglutide, lixisenatide (2016), abliglutide (2014) and dulaglutide. The main advantage of GLP over sulfonylureas or meglitinides is that hypoglycemia can be avoided. On the contrary, these medications may affect the pancreas as DPP-4I drugs ${ }^{76,77}$.Up to date, two more agonists are under investigation taspoglutaide and semaglutide. Nonetheless, some undesirable adverse effects of GLP-1 receptor agonists include diarrhea, nausea, and vomiting. Additionally, hypoglycemia occurred in several cases during clinical trials and it was related with concomitant insulin or insulin secretagogues. Nowadays, all guidelines suggest GLP-1 receptor agonists as potential add-on therapy to metformin for patients with uncontrolled type II diabetes. It can be concluded that long-term safety of these drugs is unspecified given their limited time on the market ${ }^{78}$.

\section{Future Perspectives}

A number of potential therapies for DM are recently being investigated. The current insulin therapy includes subcutaneous injection, which regularly fails to emulate the glucose homeostasis that normal individuals eventuate. This fact generates numerous experiments in order to develop a safer and more effective non-invasive route for insulin delivery. It is widely reported that oral delivery is the most convenient administration route. However, insulin cannot be well absorbed orally because can be rapidly degrade via enzymatic cleavage in the gastrointestinal tract. Nanotechnology plays a key role in future marketed products. Several polymeric nanoparticles and nanocarriers such as liposomes, dendrimers and micelles have been studied in order to safely develop new medications $^{79-81}$. The main properties of such nanoparticles are to present stability in gastrointestinal tract, be nontoxic and biocompatible as well as to be easily developed on a large scale. Moieties conjugation in order to prepare permeationenhanced properties and high bioavailability revealed promising results indicating that nanoparticle based systems for insulin delivery could be advantageous for DM managements. Among others, herbal plants possess therapeutic values 
against DM. In fact, some ingredients of folklore medicinal plants seem to reveal hypoglycemic activity, antioxidant action and antidiabetic activity with desirable properties $^{82-84}$.

\section{CONCLUSION}

Diabetes mellitus a metabolic disease and its management have aware the clinicians in all over the countries. In current status, a high number of populations have this disease which is related with the modern life style, unhealthy diet and sedentary life. The management of Diabetes Mellitus for Type I, is usually injectable insulin delivery in contrast to Type II which the majority of drugs are orally administered. Currently, the management of Type II diabetes focuses on glucose control via lowering of fasting and postprandial blood glucose and hemoglobin $\mathrm{A}(1 \mathrm{c})$. In the foreseeable future, researchers believe that the replacement of subcutaneous injections of insulin with nanocarriers could improve the quality of diabetic patients. Furthermore, reducing of blood sugar levels with active ingredients of plants either as primary treatment or as adjunct therapy to conventional medications is a hopeful therapy.

\section{REFERENCES}

1. World Health Organization. Global Report on Diabetes. 2016, 88.

2. Piero, M. N. Diabetes Mellitus - a Devastating Metabolic Disorder. Asian J. Biomed. Pharm. Sci. 2015, 4 (40), 1-7.

3. Patlak, M. New Weapons to Combat an Ancient Disease: Treating Diabetes. FASEB J. 2002, 16 (14), 1853.

4. Ahmed, A. M. History of Diabetes Mellitus. Saudi Med. J. 2oo2, 23 (4), 373-378.

5. White Jr. J.R. A Brief History of the Development of Diabetes Medications. Diabetes Spectr. 2014, 27 (2), 82-86.

6. Link, C. L.and McKinlay, J. B. Disparities in the Prevalence of Diabetes: Is It Race/ethnicity or Socioeconomic Status? Results from the Boston Area Community Health (BACH) Survey. Ethn. Dis. 2009, 19 (3), 288-292.

7. Miller, S. T.; Schlundt, D. G.; Larson, C.; Reid, R.; Pichert, J. W.; Hargreaves, M.; Brown, A.; McClellan, L.; Marrs, M. Exploring Ethnic Disparities in Diabetes, Diabetes Care, and Lifestyle Behaviors: The Nashville REACH 2010 Community Baseline Survey. Ethn. Dis. 2oo4, 14 (3 Suppl 1), S38-45.

8. Heidemann, D. L.; Joseph, N. A.; Kuchipudi, A.; Perkins, D. W.; Drake, S. Racial and Economic Disparities in Diabetes in a Large Primary Care Patient Population. Ethn. Dis. 2016, 26 (1), 85-90.

9. Diagnosis and Classification of Diabetes Mellitus. Diabetes Care 2o1o, 33 (Supplement_1), S62-S69.

10. Diagnosis and Classification of Diabetes Mellitus. Diabetes Care 2o13, 36 (Supplement_1), S67-S74. 
11. Tan, Y.; Chang, S. K. C.and Zhang, Y. Comparison of $\alpha$-Amylase, $\alpha$-Glucosidase and Lipase Inhibitory Activity of the Phenolic Substances in Two Black Legumes of Different Genera. Food Chem. 2017, 214, 259-268.

12. Rossi, E. J.; Sim, L.; Kuntz, D. A.; Hahn, D.; Johnston, B. D.; Ghavami, A.; Szczepina, M. G.; Kumar, N. S.; Sterchi, E. E.; Nichols, B. L.; Pinto, B. M.; Rose, D. R. Inhibition of Recombinant Human Maltase Glucoamylase by Salacinol and Derivatives. FEBS J. 2oo6, 273 (12), 2673-2683.

13. http://www.diabetesatlas.org/resources/2015-atlas.html

14. Diagnosis and Classification of Diabetes Mellitus. Diabetes Care 2014, 37(Supplement_1), S81-S90.

15. Gale, E. The Discovery of Type 1 Diabetes. Diabetes 2oo1, 5o, 217-226.

16. Wu, H.; Walker, J.; Damhuis, R. A.; Brewster, D. H.; Wild, S. H. Metformin and Survival of People with Type 2 Diabetes and Pleural Mesothelioma: A Population-Based Retrospective Cohort Study. Lung Cancer 2016, 99, 194-199.

17. Olokoba, A. B.; Obateru, O. A.and Olokoba, L. B. Type 2 Diabetes Mellitus: A Review of Current Trends. Oman Med. J. 2012, 27 (4), 269-273.

18. Standards of Medical Care in Diabetes--2014. Diabetes Care 2014, 37 (Supplement_1), S14-S80.

19. Standards of Medical Care in Diabetes-2015 Abridged for Primary Care Providers. Clin. Diabetes 2015, 33 (2), 97-111.

20. Milligan, S. Combination Therapy for the Improvement of Long-Term Macrovascular and Microvascular Outcomes in Type 2 Diabetes: Rationale and Evidence for Early Initiation. $J$. Diabetes Complications 2016, 30 (6), 1177-1185.

21. Inzucchi, S. E.; Bergenstal, R. M.; Buse, J. B.; Diamant, M.; Ferrannini, E.; Nauck, M.; Peters, A. L.; Tsapas, A.; Wender, R.; Matthews, D. R. Management of Hyperglycemia in Type 2 Diabetes, 2015: A Patient-Centered Approach: Update to a Position Statement of the American Diabetes Association and the European Association for the Study of Diabetes. Diabetes Care 2015, 38 (1), 140-149.

22. Garber, A. J.; Abrahamson, M. J.; Barzilay, J. I.; Blonde, L.; Bloomgarden, Z. T.; Bush, M. A.; Dagogo-Jack, S.; DeFronzo, R. A.; Einhorn, D.; Fonseca, V. A.; Garber, J. R.; Garvey, W. T.; Grunberger, G.; Handelsman, Y.; Henry, R. R.; Hirsch, I. B.; Jellinger, P. S.; McGill, J. B.; Mechanick, J. I.; Rosenblit, P. D.; Umpierrez, G. E. Consensus statement by the AmericN Association of clinical endocrinologists and American College of Endocrinology on the comprehensive type2 diabetes management algorithm-2016 executive summary. Endocr. Pract. 2016, 22 (1), 84-113.

23. McMillan, T.; Girgis, R.and Sellers, E. A. C. Neonatal Diabetes and Protein Losing Enteropathy: A Case Report. BMC Med. Genet. 2016, 17 (1), 32.

24. Chakraborty, P. P.; Ray, S.; Bhattacharjee, R.; Ghosh, S.; Mukhopadhyay, P.; Mukhopadhyay, S.; Chowdhury, S. First Presentation of Diabetes as Diabetic Ketoacidosis in a Case of Friedreich's Ataxia. Clin. Diabetes 2015, 33 (2), 84-86.

25. Han, B.; Zhai, H.; Yu, J.; Xia, F.; Lu, Y. Diabetes Mellitus Associated with Pancreatic Somatostatin Tumor: A Case Report. J. Clin. Transl. Endocrinol. Case Reports 2016, 2, 20-22.

26. Shaikh, S. T.; Jadhav, S. S.; Shivane, V. K.; Lila, A. R.; Bandgar, T. R.; Shah, N. S. Childhood 
Onset of Sulfonylurea Responsive Neonatal Diabetes Due to a Novel Homozygous Autosomal Recessive Mutation in the ABCC8 Gene Which Was Presumed to Be Type 1B Diabetes Before Genetic Analysis. AACE Clin. Case Reports 2016, 2 (2), e117-e121.

27. Faundez, T.; Klee, P.; Hanquinet, S.; Schwitzgebel, V.; Burkhard, P. R.; Korff, C. M. Diabetic Striatopathy in Childhood: A Case Report. Pediatrics 2016, 137 (4).

28. Arce, K. M.and Pantalone, K. M. Not All Diabetes in Infants Is Type 1: A Case Report. Diabetes Ther. 2016, 7 (2), 369-375.

29. Saleh, A. Diagnosis of Type 1 Diabetes Mellitus in Adulthood - a Case Report. 2015, 44 (4), 233-235.

30. Kumar, R. S.; Singhi, P. K.and Kakkandki, K. Case Report of Two Cases of Patella Subacute Osteomyelitis in Diabetic Women A Rare Entity. J. Orthop. Case Reports 2016, 6 (2), 13-15.

31. Prasad, K. T.; Sehgal, I. S.; Shivaprakash, M. R.; Dhooria, S. Uncommon Mycosis in a Patient with Diabetes. BMJ Case Rep. 2016, bcr2016214453.

32. Saul, S. R.; Aleksic, S.and Magnotti, M. A Patient with Newly Diagnosed Diabetes Presenting with Sino-Orbital Mucormycosis. AACE Clin. Case Reports 2016, 2 (1), e41-e45.

33. Standards of Medical Care in Diabetes - 2016. Diabetes Care 2016, 39 (1), S1-S112.

34. Perkins, B. A.; Cherney, D. Z. I.; Partridge, H.; Soleymanlou, N.; Tschirhart, H.; Zinman, B.; Fagan, N. M.; Kaspers, S.; Woerle, H.-J.; Broedl, U. C.; Johansen, O.-E. Sodium-Glucose Cotransporter 2 Inhibition and Glycemic Control in Type 1 Diabetes: Results of an 8-Week Open-Label Proof-of-Concept Trial. Diabetes Care 2014, 37 (5), 1480-1483.

35. Liu, W.and Yang, X.-J. The Effect of Metformin on Adolescents with Type 1 Diabetes: A Systematic Review and Meta-Analysis of Randomized Controlled Trials. Int. J. Endocrinol. 2016, 2016, 1-12.

36. Inzucchi, S. E.; Bergenstal, R. M.; Buse, J. B.; Diamant, M.; Ferrannini, E.; Nauck, M.; Peters, A. L.; Tsapas, A.; Wender, R.; Matthews, D. R.; American Diabetes Association (ADA); European Association for the Study of Diabetes (EASD). Management of Hyperglycemia in Type 2 Diabetes: A Patient-Centered Approach: Position Statement of the American Diabetes Association (ADA) and the European Association for the Study of Diabetes (EASD). Diabetes Care 2012, 35 (6), 1364-1379.

37. Maruthur, N. M.; Tseng, E.; Hutfless, S.; Wilson, L. M.; Suarez-Cuervo, C.; Berger, Z.; Chu, Y.; Iyoha, E.; Segal, J. B.; Bolen, S. Diabetes Medications as Monotherapy or Metformin-Based Combination Therapy for Type 2 Diabetes. Ann. Intern. Med. 2016, 164 (11), 1-20.

38. El-Kaissi, S.and Sherbeeni, S. Pharmacological Management of Type 2 Diabetes Mellitus: An Update. Curr. Diabetes Rev. 2011, 7 (6), 392-405.

39. Roy, H.; Brahma, C. K.; Nandi, S.; Parida, K. R. Formulation and Design of Sustained Release Matrix Tablets of Metformin Hydrochloride: Influence of Hypromellose and Polyacrylate Polymers. Int. J. Appl. basic Med. Res. 2013, 3 (1), 55-63.

40. Nanjwade, B. K.; Mhase, S. R.and Manvi, F. V. Formulation of Extended-Release Metformin Hydrochloride Matrix Tablets. Trop. J. Pharm. Res. 2011, 10 (4), 375-383.

41. Patil, S. A.; Kuchekar, B. S.; Chabukswar, A. R.; Jagdale, S. C. Formulation Evaluation of Extended-Release Solid Dispersion of Metformin Hydrochloride. J. Young Pharm. 2010, 2 (2), 121-129. 
42. Jagdale, S.; Patil, S.; Kuchekar, B.; Chabukswar, A. Preparation and Characterization of Metformin Hydrochloride - Compritol 888 ATO Solid Dispersion. J. Young Pharm. 2011, 3 (3), 197-204.

43. Parveen, R.; Singh, A. P.; Kumar Bhargav, R.; Verma, A.; Priyanka, S. Formulation and evaluation of floating tablet of Metformin HCL. World J. Pharm. Pharm. Sci. 2016, 5 (7), $1317-1326$.

44. Kumar, C. S.; Raja, M. D.; Sundar, D. S.; Gover Antoniraj, M.; Ruckmani, K. Hyaluronic Acid Co-Functionalized Gold Nanoparticle Complex for the Targeted Delivery of Metformin in the Treatment of Liver Cancer (HepG2 Cells). Carbohydr. Polym. 2015, 128, 63-74.

45. Seino, S. Cell Signalling in Insulin Secretion: The Molecular Targets of ATP, cAMP and Sulfonylurea. Diabetologia 2012, 55 (8), 2096-2108.

46. Davidson, J. Clinical Diabetes Mellitus: A Problem-Oriented Approach Diabetes Mellitus; Thieme Medical Publishers, 2000.

47. Mudgal, S.and Pancholi, S. Formulation of Glibenclamide Solid Dispersions by Solvent Evaporation Technique. J. Chem. Pharm. Res. 2012, 4 (1), 353-359.

48. Ning, X.; Sun, J.; Han, X.; Wu, Y.; Yan, Z.; Han, J.; He, Z. Strategies to Improve Dissolution and Oral Absorption of Glimepiride Tablets: Solid Dispersion versus Micronization Techniques. Drug Dev. Ind. Pharm. 2011, 37 (6), 727-736.

49. Mehsud, S. U.; Khan, G. M.; Hussain, A.; Akram, M.; Akhlaq, M.; Khan, K. A.; Shakoor, A. Controlled Release Matrix Tablets of Glipizide: Influence of Different Grades of Ethocel and Co-Excipient on Drug Release. Pak. J. Pharm. Sci. 2016, 29 (3), 779-787.

50. Maboos, M.; Yousuf, R. I.and Shoaib, M. H. Formulation Development and Optimization: Encapsulated System of Atenolol and Glyburide. Pak. J. Pharm. Sci. 2016, 29 (2), 569-577.

51. Meka, V. S.; Pillai, S.; Dharmalingham, S. R.; Sheshala, R.; Gorajana, A. Preparation and in Vitro Characterization of a Non-Effervescent Floating Drug Delivery System for Poorly Soluble Drug, Glipizide. Acta Pol. Pharm. 2015, 72 (1), 193-204.

52. Albertini, B.; Sabatino, M. Di; Melegari, C.; Passerini, N. Formulation of Spray Congealed Microparticles with Self-Emulsifying Ability for Enhanced Glibenclamide Dissolution Performance. J. Microencapsul. 2015, 32 (2), 181-192.

53. Mooranian, A.; Negrulj, R.; Al-Sallami, H. S.; Fang, Z.; Mikov, M.; Golocorbin-Kon, S.; Fakhoury, M.; Arfuso, F.; Al-Salami, H. Release and Swelling Studies of an Innovative AntidiabeticBile Acid Microencapsulated Formulation, as a Novel Targeted Therapy for Diabetes Treatment. J. Microencapsul. 2015, 32 (2), 151-156.

54. Blicklé, J. F. Meglitinide Analogues: A Review of Clinical Data Focused on Recent Trials. Diabetes Metab. 2006, 32 (2), 113-120.

55. Tavakoli, N.; Minaiyan, M.; Tabbakhian, M.; Pendar, Y. Preparation and Evaluation of a Controlled Drug Release of Repaglinide through Matrix Pellets: In Vitro and in Vivo Studies. $J$. Microencapsul. 2014, 31 (6), 529-534.

56. Akhtar, J.; Siddiqui, H. H.; Fareed, S.; Badruddeen; Khalid, M.; Aqil, M. Nanoemulsion: For Improved Oral Delivery of Repaglinide. Drug Deliv. 2016, 23 (6), 2026-2034.

57. Sharma, M.; Kohli, S.and Dinda, A. In-Vitro and in-Vivo Evaluation of Repaglinide Loaded Floating Microspheres Prepared from Different Viscosity Grades of HPMC Polymer. Saudi Pharm. J. 2015, 23 (6), 675-682. 
58. Ebrahimi, H. A.; Javadzadeh, Y.; Hamidi, M.; Jalali, M. B. Repaglinide-Loaded Solid Lipid Nanoparticles: Effect of Using Different Surfactants/stabilizers on Physicochemical Properties of Nanoparticles. DARU J. Pharm. Sci. 2015, 23 (1), 46.

59. Gadadare, R.; Mandpe, L.and Pokharkar, V. Ultra Rapidly Dissolving Repaglinide Nanosized Crystals Prepared via Bottom-Up and Top-Down Approach: Influence of Food on Pharmacokinetics Behavior. AAPS PharmSciTech 2015, 16 (4), 787-799.

60. Hauner, H. The Mode of Action of Thiazolidinediones. Diabetes. Metab. Res. Rev.18 Suppl 2, 2002, S10-5.

61. Sanrame, C. N.; Remenar, J. F.; Blumberg, L. C.; Waters, J.; Dean, R. L.; Dong, N.; Kriksciukaite, K.; Cao, P.; Almarsson, Ö. Prodrugs of Pioglitazone for Extended-Release (XR) Injectable Formulations. Mol. Pharm. 2014, 11 (10), 3617-3623.

62. Taupitz, T.; Dressman, J. B.and Klein, S. New Formulation Approaches to Improve Solubility and Drug Release from Fixed Dose Combinations: Case Examples Pioglitazone/glimepiride and Ezetimibe/simvastatin. Eur. J. Pharm. Biopharm. 2013, 84 (1), 208-218.

63. Zhang, H.; Qadeer, A.; Mynarcik, D.; Chen, W. Delivery of Rosiglitazone from an Injectable Triple Interpenetrating Network Hydrogel Composed of Naturally Derived Materials. Biomaterials 2011, 32 (3), 890-898.

64. Mohan Kamila, M.; Mondal, N.; Kanta Ghosh, L.; Kumar Gupta, B. Multiunit Floating Drug Delivery System of Rosiglitazone Maleate: Development, Characterization, Statistical Optimization of Drug Release and In Vivo Evaluation. AAPS PharmSciTech 2009, 10 (3), 887-899.

65. Dej-Adisai, S.and Pitakbut, T. Determination of a-Glucosidase Inhibitory Activity from Selected Fabaceae Plants. Pak. J. Pharm. Sci. 2015, 28 (5), 1679-1683.

66. Zhao, H.; Zhang, Y.; Guo, Y.; Shi, S. Identification of Major a-Glucosidase Inhibitors in Radix Astragali and Its Human Microsomal Metabolites Using Ultrafiltration HPLC-DAD-MSn. J. Pharm. Biomed. Anal. 2015, 104, 31-37.

67. Uddin, G.; Rauf, A.; Al-Othman, A. M.; Collina, S.; Arfan, M.; Ali, G.; Khan, I. Pistagremic Acid, a Glucosidase Inhibitor from Pistacia Integerrima. Fitoterapia 2012, 83 (8), 1648-1652.

68. Haas, B.; Eckstein, N.; Pfeifer, V.; Mayer, P.; Hass, M. D. S. Efficacy, Safety and Regulatory Status of SGLT2 Inhibitors: Focus on Canagliflozin. Nutr. Diabetes 2014, 4, e143.

69. Powell, J.; Miller, S. A.and Taylor, J. R. Sodium-Glucose Cotransporter 2 Inhibitors: The New Option for Diabetes Mellitus Management. South. Med. J. 2015, 108 (2), 82-90.

70. Wu, J. H. Y.; Foote, C.; Blomster, J.; Toyama, T.; Perkovic, V.; Sundström, J.and Neal, B. Effects of Sodium-Glucose Cotransporter-2 Inhibitors on Cardiovascular Events, Death, and Major Safety Outcomes in Adults with Type 2 Diabetes: A Systematic Review and Meta-Analysis. Lancet Diabetes Endocrinol. 2016, 4 (5), 411-419.

71. Brunton, S. GLP-1 Receptor Agonists vs. DPP-4 Inhibitors for Type 2 Diabetes: Is One Approach More Successful or Preferable than the Other? Int. J. Clin. Pract. 2014, 68 (5), 557-567.

72. Behme, M. T.; Dupré, J.and McDonald, T. J. Glucagon-like Peptide 1 Improved Glycemic Control in Type 1 Diabetes. BMC Endocr. Disord. 2oo3, 3 (1), 3.

73. Koliaki, C.and Doupis, J. Incretin-Based Therapy: A Powerful and Promising Weapon in the Treatment of Type 2 Diabetes Mellitus. Diabetes Ther. 2011, 2 (2), 101-121.

74. Chen, M.; Liu, Y.; Jin, J.and He, Q. The Efficacy and Safety of Dipeptidyl Peptidase-4 In- 
hibitors for Treatment of Type 2 Diabetes Mellitus Patients with Severe Renal Impairment: A Meta-Analysis. Ren. Fail. 2016, 38 (4), 581-587.

75. Karagiannis, T.; Boura, P.and Tsapas, A. Safety of Dipeptidyl Peptidase 4 Inhibitors: A Perspective Review. Ther. Adv. Drug Saf. 2014, 5 (3), 138-146.

76. Trujillo, J. M.; Nuffer, W.and Ellis, S. L. GLP-1 Receptor Agonists: A Review of Head-toHead Clinical Studies. Ther. Adv. Endocrinol. Metab. 2015, 6 (1), 19-28.

77. Kalra, S.; Baruah, M.; Sahay, R.; Unnikrishnan, A.; Uppal, S.; Adetunji, O. Glucagon-like Peptide-1 Receptor Agonists in the Treatment of Type 2 Diabetes: Past, Present, and Future. Indian J. Endocrinol. Metab. 2016, 20 (2), 254.

78. Prasad-Reddy, L.and Isaacs, D. A Clinical Review of GLP-1 Receptor Agonists: Efficacy and Safety in Diabetes and beyond. Drugs Context 2015, 4, 1-19.

79. Sharma, G.; Sharma, A. R.; Nam, J.-S.; Doss, G. P. C.; Lee, S.-S.; Chakraborty, C. Nanoparticle Based Insulin Delivery System: The next Generation Efficient Therapy for Type 1 Diabetes. J. Nanobiotechnology 2015, 13 (1), 74.

80. Alai, M. S.; Lin, W. J.and Pingale, S. S. Application of Polymeric Nanoparticles and Micelles in Insulin Oral Delivery. J. Food Drug Anal. 2015, 23 (3), 351-358.

81. Subramani, K. and Pathak, S. Recent Trends in Diabetes Treatment Using Nanotechnology. 2012, 7 (1), 85-95.

82. Ezuruike, U. F. and Prieto, J. M. The Use of Plants in the Traditional Management of Diabetes in Nigeria: Pharmacological and Toxicological Considerations. J. Ethnopharmacol. 2o14, 155 (2), 857-924.

83. Patel, D. K.; Kumar, R.; Laloo, D.; Hemalatha, S. Diabetes Mellitus: An Overview on Its Pharmacological Aspects and Reported Medicinal Plants Having Antidiabetic Activity. Asian Pac. J. Trop. Biomed. 2012, 2 (5), 411-420.

84. Rahimi, M. A Review: Anti Diabetic Medicinal Plants Used for Diabetes Mellitus. Bull. Environ. Pharmacol. Life Scienes 2015, 4 (2), 163-180.

(Received 29 August 2016; accepted 14 November 2016) 